\title{
Effects of Context-Based Instructional Approaches on Students' Problem-Solving Skills in Rotational Motion
}

\author{
Fikadu Eshetu ${ }^{1,2^{\star}}$, Shimeles Assefa ${ }^{3}$ \\ ${ }^{1} \mathrm{PhD}$ candidate, Department of Science and Mathematics Education, Addis Ababa University, ETHIOPIA \\ 2 Lecturer, Jigjiga University, ETHIOPIA \\ ${ }^{3}$ Associate Professor, Department of Science and Mathematics Education, Addis Ababa University, ETHIOPIA
}

Received 14 February 2018 - Revised 28 September 2018 - Accepted 28 November 2018

\begin{abstract}
This study investigated the effect of context-based instructional approaches on students' problem-solving skills using quasi-experimental design. A total of 166 eleventh grade students participated in the study. Data were collected using problemsolving skill test. A REACT (Relating, Experiencing, Applying, Cooperating and Transferring) strategy of context-based instruction and traditional instruction integrated with the REACT strategy of context-based instruction were used to teach treatment group I and treatment group II students, respectively while the traditional method was used in the comparison group. The result shows the existence of mean differences between the groups in favor of the treatment groups. But this difference was not statistically significant. Therefore, the traditional problem-solving strategies did not have a significant impact on students' problems solving skills although active learning strategies were used. Hence, we suggest the concomitant use of active learning method(s) and more recent problem-solving strategies. On the other hand, the gender gap was not that much significant in the treatment groups and hence, the approaches can work for both genders.
\end{abstract}

Keywords: context-based instructional approaches, traditional instruction, problemsolving skills, rotational motion

\section{INTRODUCTION}

Problem-solving is a complex process that is helpful in our day-to-day life and is also crucial in the teaching and learning process related to Science Technology Engineering and Mathematics (STEM) fields (Docktor et al, 2016). Particularly, physics instructors commonly use problem-solving so as to teach and assess students' learning of physics contents. This shows the importance of problem-solving to a physics instruction (Gerace \& Beatty, 2005).

According to McCormick (1997), the two types of knowledge required for solving technical problems are procedural and conceptual knowledge. The knowledge, skills and tools which are necessary for solving problems are known as conceptual knowledge. On the other hand, the process skills used in solving problems are procedural knowledge. Problem-solving process occurs when students' need to resolve a situation where they do not know a specific set of actions to follow so as to reach to a solution (Newell \& Simon, 1972). However, for efficiently helping students, researchers and educators need more information about problem solving process (Armagan, Sagir \& Çelik, 2009). If problem solving skill is a cognitive activity then, improving problem solving skill through education should be a valuable goal (Seminara, 1996).

To support the development of problem-solving skills, it is crucial to have tools that can measure the difference between novice and expert problem-solvers performance in classrooms (Docktor et al., 2016). According to Reif and Heller (1982), the main difference between the two was on how they use and organize their knowledge when solving problems. Expert problem solvers are individuals who use the problem-solving strategies effectively and consciously whereas novice problem solvers are those who cannot use it sufficiently (Selçuk, Çalışkan, \& Erol,

(C) 2019 by the authors; licensee Modestum Ltd., UK. This article is an open access article distributed under the terms and conditions of the Creative Commons Attribution License (http://creativecommons.org/licenses/by/4.0/). \fik4jju@gmail.com (*Correspondence) $\bigotimes$ shi.assefa@gmail.com 


\section{Contribution of this paper to the literature}

- The study found that context-based instructional approaches are relatively better than the traditional instruction in enhancing students' problem-solving skills even though not statistically significant. Furthermore, the approach works for both male and female students.

- Students use mathematical formulas and specific applications without giving due emphasis to physics approach and logical progression. Hence, the traditional problem-solving strategy was not that much more effective in developing students' problem-solving skills.

- For enhancing students' problems solving skills, the study suggests the need for training students and teachers in recent problem-solving strategies besides using active learning methods.

2008). Experts use more qualitative reasoning and arguments in detail before using mathematical equations while novices rush into finding the result without understanding the conceptual base of the problem (Walsh, 2009). Students lack coherent knowledge structure for solving physics problems as expert physicists do. This difference between experts and novices are discussed under the umbrella of two categories; knowledge organization and knowledge use in many of the literature (Mestre, 1994). The review of research conducted by Mestre on problemsolving with an emphasis on the cognitive aspects of learning showed that skillful problem-solving is the result of a significant, properly cross-referenced, hierarchical organized knowledge base as well as qualitative reasoning based on conceptual knowledge. In order to highlight the role of conceptual knowledge in problem solving, students should be encouraged to incorporate a qualitative 'strategy' when solving problems (Leonard et al., 1996). Mestre (1994), together with others (Dufresne, Gerace, Hardiman, \& Mestre, 1992; Hardiman, Dufresne, \& Mestre, 1989; Mualem \& Eylon, 2007), calls for a reform in problem-solving instruction that emphasizes on instruction that encourages qualitative reasoning.

There are many problem-solving strategies that show the process from low to high complexity (Yu, Fan, \& Lin, 2014). However, after testing many different combinations of categories and scoring different types of written solutions to a problem with different raters, Docktor et al. (2016) arrived at the five categories of the Minnesota Assessment of Problem-Solving (MAPS) rubric as being the simplest and reliable for implementing it at large scale. This rubric consists of the useful description, physics approach, specific application, mathematical procedures and logical progression components; and is used to assess the students' written solution to a problem. The rubric should be employed by teachers so as to guide their pedagogy (Docktor et al., 2016). The study conducted by Shishigu, Hailu, and Anibo (2017) used this rubric in the experimental group students after explaining to them by considering it as a teaching method and they reported a positive outcome on students' conceptual understanding as a result of the training. However, according to Kim and Pak (2002), it is difficult for the students to develop an understanding of the conceptual nature of the physics topics through solving problems quantitatively. So by only using the problem-solving strategy rubrics as an intervention, it is difficult to enhance students' conceptual understanding and subsequent problem-solving skills. However, Shishigu et al. (2017) used the rubric as a problem-based teaching method. But since the rubric is a tool for assessment of problem-solving skills, it can be used in student-centered as well as teacher-centered classrooms as it was not a teaching method by itself.

On the other hand, previous work by different researchers shows evidence about the enhancement of students' problem-solving skills via active teaching and learning methods (Heller et al., 1992; Shishigu, Bashu, Tesfaw, \& Gadisa, 2016). One of the active teaching methods that obtained much emphasis through literatures is the contextbased instructional approach. The contextual approaches to physics come out in response to perception of students' that physics is impersonal, objective and inappropriate to everyday life (Lye, Fry, \& Hart, 2001). Bennett (2003) defines a context-based teaching strategy as an approach used in science/physics teaching by making use of contexts and application of science as the starting point in developing scientific ideas, concepts and principles on students. Context-based instructional approaches put into account students' 'life world' as a starting point of the teaching method. It thus refers to an instructional approach using real life contexts and situations that students face in their everyday life as a starting point for enhancing students understanding of scientific ideas.

One of the teaching strategies for contextual teaching and learning suggested by the Center for Occupational Research and Development (CORD) is the REACT strategy: Relating, Experiencing, Applying, Cooperating, and Transferring (CORD, 1999). On the other hand, there is a risk in moving an instruction in one step from a noncontextual traditional approach to a fully contextualized approach since this form of constructivist teaching requires more time than the usual lecture method that the students are familiar with it (Rayner, 2005). Due to this reason, the researchers integrated the conventional/traditional teaching method with a context-based instruction. Hence, the REACT strategies of context-based instruction as well as the traditional method integrated with the REACT strategy of context-based instruction are the context-based instructional approaches that are used in this study. 
Table 1. Research design

\begin{tabular}{lllll}
\hline Treatment group I & $\mathrm{N}$ & $\mathrm{O}_{1}$ & $\mathrm{X}_{1}$ & $\mathrm{O}_{2}$ \\
\hline Treatment group II & $\mathrm{N}$ & $\mathrm{O}_{1}$ & $\mathrm{X}_{2}$ & $\mathrm{O}_{2}$ \\
\hline Comparison group & $\mathrm{N}$ & $\mathrm{O}_{1}$ & & $\mathrm{O}_{2}$ \\
\hline
\end{tabular}

Note. $\mathrm{N}=$ represents the non randomization of subjects to groups; $\mathrm{O}_{1}=$ represents the pre-test; $\mathrm{O}_{2}=$ represents the post-test; $\mathrm{X}_{1}$ $=$ represents the REACT strategy of context-based instruction; $X_{2}=$ represents the conventional method integrated with the REACT strategy of context-based instruction

The impact of context-based approaches on secondary school students' physics learning has been analyzed in numerous research studies so far, and it is good in enhancing students' achievement, conceptual understanding of the topics being taught and affection of physics (Taasoobshirazi \& Carr, 2008). However, its impact on some other higher level skills such as problem-solving skills had not been explored as such (Panprueksa, 2012; Pesman, 2012). According to Assefa (2016), lack of conceptual understanding may undermine student's performance in procedural understanding tests. Furthermore, although it is an issue of debate, some researchers argue that conceptual understanding should be enhanced before problem-solving skills (Crouch \& Mazur, 2001; Kim \& Pak, 2002; McDermott et al., 2002). Therefore, understanding of concepts as a result of context-based instructional approaches may lead to the generation of new procedures and new problem-solving skills.

So in this study, the effect of context-based instructional approaches on students' problem-solving skills in physics was investigated. The MAPS rubric was used to assess the students' written solution to the open ended tests. The effects of these instructional approaches were also investigated with regard to gender. Among the physics topics, rotational motion was selected for the investigation since rotational motion is a difficult and conceptually rich topic that needs further attention from the physics education research community (Mashood \& Singh, 2015). According to a study conducted by Duman, Demirci, and Şekercioğlu (2015), students have difficulties and misconceptions about the fundamental concepts of rotational motion, such as rolling, moment of inertia, rotational energy and torque concepts. In addition to these, physics education research on concepts related to rotational motion is limited (Mashood \& Singh, 2015). Therefore, in this study attempts were made to test the following null hypotheses as the research is purely quantitative:

$\mathbf{H}_{\mathbf{0 1}}$ : There is no statistically significant mean difference between students exposed to context-based instructional approaches and those exposed to traditional instruction in their skills of solving problems related to rotational motion.

$\mathbf{H}_{\mathbf{0} 2}$ : There is no statistically significant mean difference between students exposed to the REACT strategy of context-based instruction and those exposed to the traditional instruction integrated with the REACT strategy of context-based instruction in their skills of solving problems related to rotational motion.

$\mathbf{H}_{\mathbf{0}}$ : There is no significant mean difference between male and female students exposed to context-based instructional approaches in their skills of solving problems.

\section{METHOD OF THE STUDY}

\section{Design}

This study used a pre-test - post-test non equivalent group quasi - experimental design to compare the two treatment groups with the comparison group. The use of a quasi-experimental design was necessitated by the difficulty of randomly assigning subjects to the comparison and treatment groups and lack of control of the treats of validity which is inherent in a school setting. Table 1 shows the symbolic representation of the multiple treatments quasi - experimental design used in the study.

\section{Sampling}

The study was conducted in Robe, Batu Terara and Ginnir preparatory schools in the Bale zone of Oromia regional state, Ethiopia. The students in these three government schools come from families with almost similar socioeconomic status and their demographic distribution is also urban-rural. So as to control for teacher variable, three teachers (one from each school) that are approximately equivalent to each other in terms of their experience, qualification and willingness to participate in the study were selected from the available teachers. After that, among the sections taught by the selected teachers, three sections (one from each of the schools) that are approximately equivalent to each other based on their first semester result were purposely selected from the available sections of grade 11. Prior to administering the instrument as a pre-test, the sampled section from Batu Terara, Robe and Ginnir preparatory schools were randomly assigned to treatment group I, treatment group II and the comparison group, respectively using a lottery method. Table 2 presents the data related to the participants in each group. 
Table 2. Participants number in each group

\begin{tabular}{|c|c|c|c|c|c|}
\hline & & \multicolumn{4}{|c|}{ Group } \\
\hline \multirow{4}{*}{ Gender } & & Treatment group I & Treatment group II & Comparison group & Total \\
\hline & Male & 31 & 28 & 35 & 94 \\
\hline & Female & 22 & 28 & 22 & 72 \\
\hline & Total & 53 & 56 & 57 & 166 \\
\hline
\end{tabular}

\section{Data Collection Instrument}

With the aim of finding answers to the research hypotheses, the problem-solving skill test was used to collect data. This test consists of six workout problems related to rotational motion that was developed by the researchers based on the objectives stated in the students' text book. Several discussions among the researchers were conducted to assure the content and face validity of the items. Further validation was also made by giving the draft test for experts and practitioner teachers. After appropriate modifications, according to the feedback obtained from the experts and teachers, the test was pilot tested on another school which was not involved in an actual study. After the pilot study, the calculated value for the internal consistency reliability of the test was 0.72 . Thus, according to Fraenkel and Warrel (1996) and others, the test used in this research was found to be in high reliability range as it is between 0.70 and 1.0. Hence, the test was administered to the actual sources of information.

To assess the students written solutions to rotational motion problems, the five categories MAPS rubric were used. It consists of summarizing information regarding the problem into a useful description, deciding on an appropriate physics approach based on principles, choosing a specific application of physics to the conditions in a problem, pursuing proper mathematical procedures and having structured, goal-oriented logical progression that direct the problem solution process (Docktor et al., 2016). The rubric can be applicable to different physics topics as well as problem types, ranging from those usually found in textbooks to context-rich problems (Docktor et al., 2016). For each solution to a problem, an overall rubric score (with a maximum of 25) was obtained by assigning a value between 0 and 5 for each written solution of the five categories of the rubric and then summing all the scores or the values together. Then, the obtained summed score was divided by the number of categories of the rubric having a numeric value. This way the results obtained for each of the six items was added together and converted to 20 just for the sake of analysis.

\section{Procedure}

After analyzing the feedbacks obtained from the experts and a pilot study, items which need modification were revised. Before the intervention, the two physics teachers who taught the treatment groups were given training on how to implement the treatment in the classroom. Although, the pre-test scores are likely not meaningful as the students don't have enough background knowledge to understand the problem-solving skill performance questions that used some physics formalism, the sample students in the three groups were administered the instruments as a pre-test.

During the intervention period, treatment group I students' were taught using the REACT strategy (Relating, Experiencing, Applying, Cooperating and Transferring) of context-based instruction. The teaching process started by revealing students' ideas about the topic. This helped the teacher to get idea about students' prior knowledge. At this stage, the teacher linked the target concept with a context. Then, the teacher provided a suitable learning environment for the students to compare the concepts with their experience. Here, the students learnt the topics in the context of exploration. The teacher also gave students exclusive learning activities that help them to gain experience related to the concept they are learning. After that, the students learnt by applying the concepts to real life activities which help them to see the value of learning. This was done through solving problems and then interpreting their results and creating concepts by connecting it with real life or context. Thus, the concept was constructed and related to real life. Here, the teacher explained the topic by relating the concept with the given context. Students learnt the topics through sharing, replying and communicating with each other. Finally, the teacher showed the students on how to transfer the knowledge they acquired to real life situations. In other words, the teacher encouraged the students to use the explanations in new situations.

In treatment group II, the traditional teaching method integrated with the REACT strategy of context-based instruction is used. This teaching method is a type of teacher-student interactive method which consists of relating, presenting, applying, transferring and evaluating stages with cooperation and discussion at all stages. Using this technique, the teacher revealed students' ideas about the topic. Responses of the students' were taken and they were discussed by linking the concept with a context. Afterwards, the teacher shifted from the contextual discussion to physics content. The physics content was presented to the students using the traditional teaching method. So the teacher explained the concept to the students and also solved problems. After the presentation of the content, the 
Table 3. Cross-tabulation of gender versus groups on pre-test scores

\begin{tabular}{|c|c|c|c|c|c|c|c|c|c|c|}
\hline & & \multicolumn{9}{|c|}{ Group } \\
\hline & & \multicolumn{3}{|c|}{ Treatment group I } & \multicolumn{3}{|c|}{ Treatment group II } & \multicolumn{3}{|c|}{ Comparison group } \\
\hline & & $\mathbf{N}$ & $\mathbf{M}$ & SD & $\mathbf{N}$ & $\mathbf{M}$ & SD & $\mathbf{N}$ & $\mathbf{M}$ & SD \\
\hline \multirow{3}{*}{ Gender } & $M$ & 31 & 0.90 & .29 & 28 & 0.62 & .33 & 35 & 0.22 & .26 \\
\hline & $F$ & 22 & 0.36 & .25 & 28 & 0.28 & .27 & 22 & 0.18 & .26 \\
\hline & Total & 53 & 0.63 & .29 & 56 & 0.43 & .31 & 57 & 0.20 & .26 \\
\hline
\end{tabular}

Table 4. Mean Comparison of the pre-test scores by groups

\begin{tabular}{|c|c|c|c|c|c|}
\hline Variable & Sum of Squares & df & Mean Square & $\mathbf{F}$ & $\mathbf{P}$ \\
\hline Between Groups & 1.36 & 2 & .68 & 8.15 & .000 \\
\hline Within Groups & 13.56 & 163 & .08 & & \\
\hline Total & 14.91 & 165 & & & \\
\hline
\end{tabular}

questions raised during the discussion were addressed again, and the moment, they were answered by relating it with the new physics content. The teacher provided a proper learning environment which helps the students to compare the concepts with their previous experience or familiar contexts. The teacher also encouraged the students to use the explanations in new situations through providing another application allowing students to use their new knowledge. Finally, the teacher tried to measure whether the students had understood the new information correctly.

On the other hand, the traditional or conventional teaching method used in the comparison group comprised of introduction, presentation, summary or stabilization and evaluation stages. This is the common format used by the classroom teachers throughout the country.

The study lasted for seven weeks. The content was prepared in line with the curriculum and the same content was taught in each of the three groups. When the study period is completed, the problem-solving skill test was administered as the post-test in order to compare the findings from the comparison group and the two treatment groups.

\section{Methods of Data Analysis}

After testing of the assumptions, the data was analyzed using parametric statistical tests, i.e., ANOVA and ANCOVA in addition to the descriptive statistics. ANOVA was conducted to check for the equivalence of the groups on the pre-test scores. In order to statistically control the pre-test sensitization, which in turn affects the post-test result, ANCOVA was used to analyze the post-test scores. In the ANCOVA analysis, the pre-test scores is used as covariates. All statistical tests were computed using SPSS software. A value of p less than 0.05 was considered to be statistically significant.

\section{RESULTS}

After administering the instrument as a pre-test, the mean score results obtained were tabulated as shown in Table 3.

As can be seen in Table 3, the pre-test mean scores of the groups are all different. The mean of the students' pre-test scores for the comparison group is 0.20 where it corresponds to 0.63 in the treatment group I and 0.43 in treatment group II. To find out whether the differences between the pre-test mean scores of the students' were statistically significant or not, ANOVA was conducted. The result is presented in Table 4.

Although the mean difference between the groups looks small, the results of the analysis showed the existence of a statistically significant mean difference between the groups on the pre-test $(F(2,163)=8.15, p=0.000<0.05)$. The result of Tamhane's T2 post-hoc tests indicated that the problem-solving skill pre-test mean scores of the students' in the two treatment groups were significantly higher than the mean scores of the comparison group. Hence, so as to create a statistically equivalent groups, ANCOVA was used to trim off the initial differences in pretest mean scores so that the post-test scores were analyzed against equivalent pre-test scores.

Following the treatments, the mean of the post-test scores rises to 9.21 and 9.32 , respectively, for the treatment group I and II while it increases to 7.66 for the comparison group as shown in Table 5. 
Table 5. Cross-tabulation of gender versus groups on post-test scores

\begin{tabular}{|c|c|c|c|c|c|c|c|c|c|c|c|c|c|}
\hline & & & & & \multicolumn{9}{|c|}{ Group } \\
\hline & & \multicolumn{4}{|c|}{ Treatment group I } & \multicolumn{4}{|c|}{ Treatment group II } & \multicolumn{4}{|c|}{ Comparison group } \\
\hline & & $\mathbf{N}$ & $\mathbf{M}$ & $\mathbf{M}_{\mathbf{a}}$ & SD & $\mathbf{N}$ & $\mathbf{M}$ & $M_{a}$ & SD & $\mathbf{N}$ & $\mathbf{M}$ & $\mathbf{M}_{\mathbf{a}}$ & SD \\
\hline \multirow{3}{*}{ Gender } & $\mathrm{M}$ & 31 & 9.83 & 8.99 & 3.89 & 28 & 9.92 & 9.48 & 4.37 & 35 & 8.87 & 9.33 & 3.02 \\
\hline & $F$ & 22 & 8.33 & 8.40 & 3.34 & 28 & 8.73 & 9.01 & 2.87 & 22 & 5.74 & 6.32 & 3.74 \\
\hline & Total & 53 & 9.21 & 8.70 & 3.71 & 56 & 9.32 & 9.24 & 3.71 & 57 & 7.67 & 7.83 & 3.62 \\
\hline
\end{tabular}

Note. $M_{a}=$ adjusted mean

Table 6. ANCOVA results for post-test mean scores adjusted according to pre-test scores by groups.

\begin{tabular}{|c|c|c|c|c|c|}
\hline Source & df & $\mathbf{F}$ & $\mathbf{P}$ & Partial Eta squared & Observed power \\
\hline Corrected Model & 6 & 7.72 & .000 & .226 & 1.000 \\
\hline Intercept & 1 & 258.14 & .000 & .619 & 1.000 \\
\hline Pre-test & 1 & 21.61 & .000 & .120 & .996 \\
\hline Group & 2 & 2.38 & .096 & .029 & .476 \\
\hline Gender & 1 & 6.23 & .014 & .038 & .699 \\
\hline Group * Gender & 2 & 2.40 & .093 & .029 & .480 \\
\hline
\end{tabular}

Table 7. Post-test mean scores of students on the problem-solving rubric

\begin{tabular}{lcccc}
\hline & Treatment group I & Treatment group II & Comparison group & Total mean \\
\hline Useful Description & 0.56 & 0.45 & 0.44 & 0.48 \\
\hline Physics Approach & 0.19 & 0.24 & 0.11 & 0.18 \\
\hline Specific Application & 0.7 & 0.67 & 0.64 & 0.67 \\
\hline Mathematical Procedures & 0.57 & 0.63 & 0.51 & 0.57 \\
\hline Logical Progression & 0.31 & 0.31 & 0.28 \\
\hline
\end{tabular}

In the covariance analysis performed, the pre-test score was considered as covariate while the post-test score was the dependent variable. Since all the assumptions of ANCOVA were met, ANCOVA was used to test whether the students' post-test mean scores, adjusted based on the pre-test scores, showed statistically significant mean differences or not. The analysis results are shown in Table 6.

The results of ANCOVA showed that the interaction effect of the instructional methods with gender is not statistically significant $(\mathrm{F}(2,159)=2.409, \mathrm{p}=0.093>0.05$, partial eta squared $=0.029)$. The difference between the post-test mean scores of eleventh grade students learning of rotational motion were also not statistically significant when the effects of students' pre-test scores are controlled $(\mathrm{F}(2,159)=2.381, \mathrm{p}=0.096>0.05$, partial eta squared $=$ 0.029). However, the adjusted post-test means of the two treatment groups $\left(M_{a}=8.7\right.$ and $M_{a}=9.24$ for the first and second treatment groups, respectively) were larger than the comparison group $\left(\mathrm{M}_{\mathrm{a}}=7.83\right)$. The partial eta-squared value found in this study (0.029) corresponds to small to medium effect size (Cohen, 1988) and it indicates that only $2.9 \%$ of the variability in the dependent variable is explained by the instructional methods or independent variable. However, the observed power (0.476) of the study indicated the slight importance of the treatment. This indicates the slight benefits of the instructional methods to the treatment groups students when compared to the students in the comparison group even though not that much significant. Hence, the groups exposed to context-based instructional approaches acquired relatively better problem-solving skills when compared to the traditional instruction groups. However, since it was not statistically significant, hypothesis Ho1 was accepted. Although the groups taught with the traditional method integrated with the REACT strategy of context-based instruction performed relatively better than the groups with REACT strategy of context-based instruction in their skills of solving problems related to rotational motion, this difference was not again statistically significant. As a result, hypothesis Ho2 was accepted.

When we look at the problem-solving skill test mean scores of the students more closely, it can be easily seen that the students in each of the three groups have a difficulty on the problem-solving rubric used in this particular study. Table 7 shows the post-test mean scores of the students on the problem-solving rubric.

As it is observed in Table 7, the students have difficulty of doing each of the levels of the rubric. They performed the least in the physics approach and logical progression part of the rubric while they performed better in specific applications and mathematical procedures. This indicates that students use mathematical formulas and associated specific applications for learning of rotational motion without giving due emphasis to contextual description, physics approach and logical progression. This shows that it is better to train both students and teachers about the rubrics used to assess students' problem-solving skills and in techniques of using context-based instructional approach. 
On the other hand, the effects of gender on students' post-test scores were statistically significant when the effects of students' pre-test scores are controlled $(\mathrm{F}(1,159)=6.234, \mathrm{p}=0.014<0.05$, partial eta squared $=0.038)$. When we closely look at the effect of the approaches on gender on each of the three groups, a statistically significant difference was observed between male and female students found in the comparison group $(F(1,54)=12.463, p=$ $0.001>0.05$, partial eta squared $=.188$ ) only. The gender gap was, thus, bigger in the comparison group favoring male students in post-mean scores. On the other hand, although the students' scores are higher in the second treatment group, an inspection of the mean scores indicated the contribution of context-based instructional approaches to both male and female students' post-scores. Thus, hypothesis Ho3 was accepted as there is no significant difference between male and female students exposed to context-based instructional approaches in their skills of solving problems, and hence it is possible to state that the approaches are effective for both genders.

\section{DISCUSSION}

After the intervention, it was found that the students' problem-solving scores increased from the pre-test to the post-test in all the three groups. This increase in the scores of the students' from prior to the instruction to after the instruction was an anticipated outcome of the research as each of the groups experienced the application of a particular teaching method, and it were statistically significant for all the three groups. The adjusted post-mean scores of the group with the REACT strategy of context-based instruction $(\mathrm{Ma}=8.7)$ were larger than the group with the traditional instruction ( $\mathrm{Ma}=7.83$ ). Thus, the study showed improvements on students' skills of solving problems after the implementation of the REACT strategy of context-based instruction. Hence, here also the researcher didn't observe the concern raised by Rayner (2005). In a similar manner, the students' adjusted mean of the group with the traditional instruction integrated with a context-based instruction were also somewhat greater than the adjusted mean of their peers in the group with the REACT strategy of context-based instruction. This outcome shows the relative effectiveness of the traditional method integrated with a context-based instruction when compared with the usual conventional and the REACT strategy of context-based instruction in the teaching rotational motion concepts. The result of the study agrees with Peşman and Özdemir (2012) finding that reported the effectiveness of the use of traditional method with a contextual approach on the students' achievement.

Generally speaking, the adjusted mean of the students in each of the two treatment groups were somehow greater than the scores of their peers in the comparison group. But this difference was not statistically significant. Although the difference was not significant, the study result supports the findings obtained by some researchers (Heller et al., 1992; Shishigu et al., 2016) to some extent. It is possible to mention lots of reasons that contributed to the existence of a not statistically significant difference. The first one is that the students' problem-solving skill scores were analyzed with aggregate means. If achiever levels were included in the study, it is really possible to locate the factor that might have contributed to it. Secondly, due to much emphasis given to solving problems in usual physics classrooms, students think learning of physics as solving problems rather than focusing on both concepts as well as procedures. Due to this, the conventional or traditional method of teaching was also almost good in solving quantitative problems that do not require that much concept even if it was not that much effective like the active learning methodologies used in this particular study. This finding supports the results obtained by Lea (1994) and Moelter, Hoellwarth, and Knight (2005) that showed the scores of students enrolled in classes based on traditional instruction to be on average higher in quantitative problems than students enrolled in instructions emphasizing conceptual learning. This can also be considered as one of the contributing factors for the existence of a not statistically significant difference in students' post-score. The other reasons for obtaining a not significant mean difference result in the students' problem-solving skills is that most of the students scored less result in the test even though they solved the equation manipulation part correctly as the students were not that much familiar with the rubric used to score their written solution. This shows that the students solved the problems using the traditional equation-centered way of solving problems, although the students' written solution was scored using the MAPS rubric. As a result, the students and even the teachers' do not interpret the result physically. This is also evident in the post-test mean scores of the students' on the five categories of the problem-solving assessment rubric used in this study. This might have a notable impact on making the treatment groups students score not to be significant.

Traditional physics education relies on the assumption of developing students understanding of the physics concepts and principles through systematically and repeatedly solving of relatively simple problems (Leonard et al., 1996; McDermott, 1991). According to Gerace and Beatty (2005), traditional problem-solving strategies were found to be less effective. For enhancing the teaching of physics at secondary and tertiary levels, the authors indicated how the teaching methodology, including the use of problem-solving, could be re-conceptualized and restructured. They also asserted that problems usually used in traditional physics instruction are mostly goaldirected, narrow, disconnected and simplistic. When students face such problems, they tend to involve in an unwanted behaviors rather than on focusing in mental activities that enhances desirable intellectual development. Furthermore, the students construct an abstract representation of the problem using limited concepts. This makes 


\section{Worked example 6.13}

A flywheel is rotating at
1000 revolutions per minute
and has a moment of inertia
of $50 \mathrm{~kg} \mathrm{~m} \mathrm{~m}^{2}$. What is its
angular momentum?
Angular momentum $=$
moment of inertia $\times$ angular
velocity
$L=I \omega$
Angular velocity
$=\frac{1000 \times 2 \pi}{60}=\frac{100 \pi}{3} \mathrm{rad} / \mathrm{s}$
$L=50 \mathrm{~kg} \mathrm{~m} \mathrm{~m}^{2} \times \frac{100 \pi}{3} \mathrm{rad} / \mathrm{s}$
$=5233.3 \mathrm{~kg} \mathrm{~m}^{2} / \mathrm{s}$

Figure 1. Sample worked example. Adapted from "Physics Student Textbook: Grade 11," by Ministry of Education, 2010, p. 136

the students to focus on determining the final result. They usually use means-ends analysis for determining the path of the solution by way of manipulating equation.

When solving problems using the traditional techniques, less emphasis was given to appropriate concepts and principles while more emphasis was given to equations and mathematical procedures (Docktor, Strand, Mestre, \& Ross, 2015). The presentation of standard physics textbooks evidence this fact (Wilson \& Buffa, 2002; Young, Freedmand, Dandin, \& Lewis, 1999) since in standard physics textbooks, equations are presented in terms of general symbols. It, then, continue to elaborating upon what those symbols stand for. However, little guidance is presented for the students regarding when to use a particular equation to a problem (Larkin, 1981). In Ethiopia, students learn solving physics problems using the traditional techniques of solving problems. In the currently used student text book, problems are solved using the traditional techniques of solving problems as shown in the example shown in Figure 1 which is directly taken from the grade 11 physics text book (Ministry of Education, 2010; p.136).

In the above example, emphasis was given in the equation which is used to solve the problem and substitution of the given quantities into the equation. There were no interpretations of the results physically which requires the conceptual understanding of rotational motion. Due to this fact, teachers also follow the same mechanisms while solving the problems to their students. On the rubric, students performed the best on the specific application and mathematical procedure; and the least on the physics approach and logical progression. After identifying for variables and some formula which is appropriate or not, majority of these students use a plug-and chug approach to solve problems just like the examples solved in their textbooks. The students focus only on selecting an appropriate formula and substitution to obtain the final result. This indicates the attention given by the students on mathematical formulas and associated specific applications for learning of physics without giving due emphasis to contextual description, physics approach and logical progression. Therefore, although students got the correct answer by inserting the given values into formulae, they may not develop the necessary skills used to transfer their understanding to other situations which will also helps them to solve more complex problems in the real world context. As a result, students' may not develop the necessary skills for transferring their understanding to a new situation although they can solve problems quantitatively by inserting values into equations. Consequently, students were often unable to relate the results to other, more complex situations although they easily solve standard textbook problems. This is in consonance with the findings from previous studies (Ambrose, Shafer, Steinberg, \& McDermott, 1999; Kim \& Pak, 2002; Leonard, Dufresne, \& Mestre, 1996; Mazur, 1992; 1997; McDermott, Rosenquist, \& van Zee, 1987; Redish, 2005; Reif \& Scott, 1999; Trowbridge \& McDermott, 1981).

Furthermore, the study result also confirmed that most of students do not approach problem-solving in a planned or strategic manner. Among the local studies, the study conducted by Mihret (2014) also confirmed that majority of physics students had problem of using appropriate problem-solving strategies for solving physics problems as their ultimate goal were found to be obtaining the numerical answer. Students' simply rush into mathematical calculations without well understanding the concepts of the problem. As a result, once they 
completed the solution of the problem, most of the students didn't try to relate the numerical value they get to the physical reality. In other words, they fail to interpret or give meaning as they did not check their final answer with real-life situations. Hence, in finding and reporting the solutions of a physics problem, limitations are observed in students (Mihret, 2014). This is consistent with the result obtained from the literature (Walsh, Howard, \& Bowe, 2007).

Although physics instructors agree that integrating conceptual knowledge with problem-solving is a desirable goal in physics instruction (Docktor et al., 2015), traditional materials are observed when encouraging equation manipulations at the expense of understanding of concepts. Study findings have also shown that problem-solving alone does not develop a deep understanding of concepts and principles (Clement, 1982; Bowden et al., 1992; McDermott, 1984; 1991) even though there are students that can properly solve problems by developing the ability of when to use an appropriate equation for solving these problems. Hence, the traditional way of solving problems practiced within the physics classroom was not that much effective in helping students to understand concepts. This agrees with the finding reported by Gerace and Beatty (2005).

Although many studies have employed different methods and focused on different key factors to develop students' problem-solving skills, it is necessary to teach students about the functions of each of the steps involved in solving problems (Yu, Fan, \& Lin, 2014). So if our desire is to develop students' ability of applying physics concepts to physical situations and reason with them which in turn also enables them to solve different types of problems, we have to teach our students and teachers about the knowledge of appropriate problem-solving strategies in addition to using active learning methods. According to the study conducted by Yu et al. (2014), students' understanding of the steps and function of the rubrics used for solving problems would help them to solve complex, difficult and badly structured problems correctly in the future. If teachers only focus on the design process without requiring students to examine and carefully think about each of the steps and show justifications for their choice, the overall process may add nothing to the problem-solving ability of students' (McCormick, 1996). Therefore, as part of a fundamental rethinking of the instructional process, the how of solving problems must change although problem-solving should remain central to instruction, as it is explained by Gerace and Beatty (2005). To do this, awareness should be first formed on the teachers' as well as students about the rubrics used to evaluate students' problem-solving skills. Therefore, the core issue here is that the way in which we learn something should be learned (Gerace \& Beatty, 2005). According to some researchers, it is difficult for the students to develop problem-solving skills without understanding the target concepts properly (Hake, 1998; Knight, 2002). This is also evident in the results obtained in this study. This is because when students encounter simple problems, they easily solve it. However, if the problem requires them some sort of concept rather than using the formula directly, the majority of the students fails to solve it. This shows that students encounter a difficulty while solving problems that need concepts in addition to equation manipulation. Hence, the findings obtained from this study shows the need for emphasis that should be given to concepts used for solving problems. This makes students not to consider solving physics problems as a hunt for equations that are forgotten soon. This is in line with the conclusions given by Docktor et al. (2015). In addition to this, students were also observed while failing to apply the concept they understood in the problem-solving rubric as they were not familiar with it. Hence, to enhance both conceptual knowledge and problem-solving skills, students and teachers should be exposed to the problem-solving strategies as the strategies focus on the conceptual nature of the questions in addition to the arithmetic's. To sum up, the study result clearly show that, without training students about the problem-solving strategies, the use of active learning strategies like the context-based instructional approaches did not have that much significant impact on students' problems solving skills.

The other important part that was investigated in this study is the effect of context-based instructional approaches on gender related differences. Associated with gender related differences, a statistically significant difference was observed on students' grand post-test scores when their prior intervention scores are controlled. However, when we closely look at the effect of the instructional methods on gender on each of the three groups, a statistically significant difference was observed between male and female students found in the comparison group in favor of male students in post-mean scores. Therefore, in traditional classroom instructions, male students perform better than their female counterparts in problem solving skill test. This is in agreement with Zhu (2007) finding that reported the existence of gender differences in mathematical problem solving favoring male students. As a result, Zhu suggested the need to think of the ways of helping all female and male students develop problem solving abilities by using appropriate instruction. Using context-based instructional approaches, a significant increment on the mean scores of both male and female students' problem-solving skill performance was observed in both treatment groups although the students' performance was again better in the second treatment group. Thus, the gender gap was not that much significant in the treatment groups. Hence, although males and females respond differently to different instructions, the context-based instructional approaches can have the potential to narrow the gender gap shown in physics education research. This result is in agreement with Taasoobshirazi and Carr (2008). It looks that the group work that was essential during the implementation of context-based instructional approaches had contributed positively in minimizing the gender gap. Accordingly, this result may agree with 
Nieswandt's (2005) study that highlighted female students' preference of social interaction with their classmates in class activities while vice versa is valid in a review study conducted by Lubben, Bennett, Hogarth, and Robinson (2005) that reported their inclination towards non-practical activities. Thus, integrating a context that is common to all students into the teaching and learning process that engages them in a variety of learning activities is valuable for both male and female students.

\section{CONCLUSION}

This study was aimed at investigating the effect of context-based instructional approaches on students' problem-solving skills. According to the results, the REACT strategies of context-based instruction as well as the traditional instruction integrated with the REACT strategy of context-based instruction are a little bit better than the traditional instruction. Furthermore, the integrated one is better than the rest. On the rubric, students performed the best in specific application and mathematical procedure; medium in useful description and the least in the physics approach and logical progression. This shows that, in the classrooms, students solve problems using the traditional way of solving problems like the one used in their text book. Thus, the traditional way of solving problems as practiced within physics classrooms were not that much effective in helping students develop true expertise since the teachers as well as the students focus only on selecting an appropriate formula and substitution to obtain the final result. Accordingly, the teachers themselves and their students did not have the knowledge of recent problem-solving strategies like the MAPS rubric used in this study for scoring students' written solution of a problem. Hence, so as to shift students away from their focus on formulas and mathematical procedures towards problem-solving approaches based on concepts and principles of physics, we must teach or train our students and teachers about the latest problem-solving strategies in addition to using active learning strategies. Furthermore, physics textbook writers and curriculum developers should rethink of introducing latest problem-solving strategies in the physics examples included in textbooks. Therefore, in any future studies, both recent problem-solving strategy trainings and active learning methodologies should be used simultaneously for enhancing students' problems solving skills to a maximum level. With regard to gender related differences, a significant increment on the mean scores of female students' problem-solving skill performance was observed in the treatment groups. Hence, the approaches have a potential to minimize the gap between male and female students performance.

\section{ACKNOWLEDGEMENT}

The authors wish to thank the teachers and students of Batu Terara, Robe and Ginnir preparatory schools who participated in the study. The study was supported by Addis Ababa and Jigjiga Universities.

\section{REFERENCES}

Ambrose, B. S., Shafer, P. S., Steinberg, R. N., \& McDermott, L. (1999). An investigation of student understanding of single-slit diffraction and double-slit diffraction. American Journal of Physics, 67(2), 146 - 155. https://doi.org/10.1119/1.19210

Armagan, F. Ö., Sagır, S. U., \& Çelik, A. Y. (2009). The effects of students' problem solving skills on their understanding of chemical rate and their achievement on this issue. Procedia Social and Behavioral Sciences, 1, 2678-2684. https:// doi.org/10.1016/j.sbspro.2009.01.473

Assefa, S. (2016). Impact of Conceptual Change Approach on Conceptual Knowledge, Procedural Knowledge and Knowledge Transfer. Staff and Educational Development International, 20(1), 15-37.

Bennett, J. (2003). Context-based approaches to the teaching of science. In: Teaching and Learning of Science (pp. 99122). London, UK: Continuum.

Bowden, J., Dall'Alba, G., Martin, E., Laurillard, D., Marton, F., Master, G., Ramsden, P., Stephanau, A., \& Walsh, E. (1992). Displacement, velocity, and Frames of reference: Phenonemographic studies of students' understanding and some implications for teaching and assessment. American Journal of Physics, 60(3), 262 269. https:// doi.org/10.1119/1.16907

Center for Occupational Research and Development (CORD). (1999). Teaching Science Contextually: The Cornerstone of Tech Prep. Waco, Texas: CORD Communications.

Clement, J. (1982). Students' preconceptions in introductory mechanics. American Journal of Physics, 50(1), 66 - 71. https:// doi.org/10.1119/1.12989

Cohen J. (1988).Statistical power analysis for the behavioral science (2nd ed.). Hillsdale: Lawrence Erlbaum Associates.

Crouch, C. H., \& Mazur, E. (2001). Peer Instruction: Ten years of experience and results. American Journal of Physics, 69(9), 970 - 977. https:/ / doi.org/10.1119/1.1374249 
Demirci, N., Duman, İ., \& Şekercioğlu, A. (2015). University Students' Difficulties and Misconceptions on Rolling, Rotational Motion and Torque Concepts. International Journal on New Trends in Education and their Implications, 6(1), 46 - 54.Fraenkel, J.R \& Wallen, N. E. (1996). How to design and evaluate research in education. New York: McGraw Hill Inc.

Docktor, J. L., Dornfeld, J., Frodermann, E., Heller, K., Hsu, L., Jackson, K. L., ... Yang, J. (2016). Assessing student written problem solutions: A problem-solving rubric with application to introductory physics. Physical Review Physics Education Research, 12, 010130. https:/ / doi.org/10.1103/PhysRevPhysEducRes.12.010130

Docktor, J. L., Strand, N. E., Mestre, J. P., \& Ross, B. H. (2015). Conceptual problem-solving in high school physics. Physical Review Special Topics - Physics Education Research, 11, 020106. https:// doi.org/10.1103/PhysRevSTPER.11.020106

Dufresne, R. J., Gerace, W. J., Hardiman, P. T., \& Mestre, J. P. (1992). Constraining Novices to Perform Expertlike Problem Analyses: Effects on Schema Acquisition. Journal of the Learning Sciences, 3(2), 307 -331.

Gerace, W. J., \& Beatty, I. D. (2005). Teaching vs. Learning: Changing Perspectives on Problem-solving in Physics Instruction. An invited talk at the 9th Common Conference of the Cyprus Physics Association and Greek Physics Association: Developments and Perspectives in Physics - New Technologies and Teaching of Science. Nicosia, Cyprus, Feb 4-6, 2005.

Hake, R. R. (1998). Interactive-engagement versus traditional methods: A six-thousand-students survey of mechanics test data for introductory physics courses. American Journal of Physics, 66(1), 64-74. https://doi.org/10.1119/1.18809

Hardiman, P. T., Dufresne, R., J., \& Mestre, J. P. (1989). The relation between problem categorization and problemsolving among novices and experts. Memory E Cognition, 17, 627-638.

Heller, P., Keith, R., \& Anderson, S. (1992). Teaching problem-solving through cooperative grouping. Part 1: Group versus individual problem-solving. American Journal of Physics, 60, $627 \quad-\quad 636$. https://doi.org/10.1119/1.17117

Kim, E., \& Pak, S. J. (2002). Students do not overcome conceptual difficulties after solving 1000 traditional problems. American Journal of Physics, 70(7), 759 - 765. https:/ / doi.org/10.1119/1.1484151

Knight, R. D. (2002). An instructor's guide to introductory physics. Addison Wesley, San Francisco.

Larkin, J. H. (1981). Cognition of learning physics. American Journal of Physics, 49, 534. https://doi.org/10.1119/1.12667

Lea, S. M. (1994). Comparing problem-solving performance of physics students in inquire-based and traditional introductory physics courses. American Journal of Physics, 62, 627-633.

Leonard, W. J., Dufresne, R. J., \& Mestre, J. P. (1996). Using qualitative problem-solving strategies to highlight the role of conceptual knowledge in solving problems. American Journal of Physics. 64(12), 1495-1503. https:/ / doi.org/10.1119/1.18409

Lubben, F., Bennett, J., Hogarth, S. \& Robinson, A. (2005). A systematic review of the effects of context-based and Science-Technology-Society (STS) approaches in the teaching of secondary science on boys and girls, and on lower-ability pupils. In: Research Evidence in Education Library. London: EPPI-Centre, Social Science Research Unit, Institute of Education, University of London.

Lye, H., Fry, M., \& Hart, C. (2001). What does it mean to teach physics 'in context': A first case study. Australian Science Teachers, 48(1), 16-22.

Mashood, K. K., \& Singh, V. A. (2015). Rotational kinematics of a rigid body about a fixed axis: development and analysis of an inventory. European Journal of Physics, 36, 045020. https://doi.org/10.1088/01430807/36/4/045020

Mazur, E. (1992). Qualitative vs. quantitative thinking: Are we teaching the right thing? Optics and Photonics news, 3,38 .

Mazur, E. (1997). Peer instruction - A user's manual. Prentice Hall, New Jersey.

McCormick, R. (1996). Instructional methodology. In P. J. Williams \& A. P. Williams (Eds.), Technology education for teachers (pp. 63-92). Melbourne: Macmillan.

McCormick, R. (1997). Conceptual and procedural knowledge. International Journal of Technology and Design Education, 7(1-2), 141-159. https:/ / doi.org/10.1023/A:1008819912213

McDermott, L. (1984). Students' conceptions and problem-solving in mechanics. Physics Today, 37(7), 24 - 32.

McDermott, L. (1991). What we teach and what is learned - Closing the gap. American Journal of Physics, 59(4), 301315. https:/ / doi.org/10.1119/1.16539 
McDermott, L. C., Rosenquist, M. L., \& van Zee, E. H. (1987). Student difficulties in connecting graphs and physics: Examples from kinematics. American Journal of Physics, 55(6), 503-513. https:/ / doi.org/10.1119/1.15104

McDermott, L. C., Shaffer, P. S., \& the Physics Education Group at the University of Washington (2002). Tutorials in Introductory Physics. Prentice Hall, Englewood Cliffs, NJ.

Mestre, J. P. (1994). Cognitive aspects of learning and teaching science. In S.J. Fitzsimmons \& L.C. Kerpelman (Eds.), Teacher enhancement for elementary and secondary science and mathematics: Status, issues and problems (pp.3-1 3-53). Washington, DC: National Science Foundation (NSF $94-80$ ).

Mihret, Z. (2014). An investigation of students' approaches to problem-solving in physics courses. International Journal of Chemical and Natural Science, 2(1), 77-89.

Ministry of Education. (2010). Physics Student Textbook: Grade 11. Malaysia: Pearson Education Limited.

Moelter, M. J., Hoellwarth, C. \& Knight, R. D. (2005). A direct comparison of conceptual learning and problemsolving ability in traditional and studio style classrooms. Am. J. Phys., 73, 459 - 462.

Mualem, R., \& Eylon, B.S. (2007). "Physics with a smile" - Explaining phenomena with a qualitative problemsolving strategy. The Physics Teacher, 45(3), 158 - 163. https:/ / doi.org/10.1119/1.2709674

Newell, A., \& Simon, H. A. (1972). Human problem-solving. Englewood Cliffs, NJ: Prentice-Hall.

Panprueksa, K. (2012). Development of Science Instructional Model Emphasizing Contextual Approach to Enhance Analytical Thinking and Application of Knowledge for Lower Preparatory School Students (Unpublished Doctoral thesis), Srinakharinwirot University, Bangkok.

Peşman, H. (2012). Method-Approach Interaction: The Effects of Learning Cycle Vs Traditional and Contextual Vs NonContextual Instruction on 11th Grade Students' Achievement in and Attitudes Towards Physics (Unpublished Doctoral thesis), Middle East Technical University, Turkey.

Peşman, H., \& Özdemir, Ö. F. (2012) Approach-Method Interaction: The role of teaching method on the effect of context-based approach in physics instruction. International Journal of Science Education, 34(14), 2127-2145. https:/ / doi.org/10.1080/09500693.2012.700530

Rayner, A. (2005). Reflections on context-based science teaching: A case study of physics students for physiotherapy. Poster presented at the annual UniServe Science Blended Learning Symposium Proceedings. Sydney, Australia, 169-172, September 30, 2005.

Redish, E. F. (2005). Changing student ways of knowing: What should our students learn in a physics class? To be published in proceedings of World view on physics education 2005: Focusing on change, New Delhi. Retrieved from http:/ / www.physics.umd.edu/perg/papers/redish/IndiaPlen.pdf

Reif F., \& Scott, L. (1999). Teaching scientific thinking skills: Students and computers coaching each other. American Journal of Physics, 67(2), 819 - 831. https:/ / doi.org/10.1119/1.19130

Reif, F., \& Heller, J. I. (1982). Knowledge structure and problem-solving in physics. Educational Psychologist, 17(2), 102 - 127. https:/ / doi.org/10.1080/00461528209529248

Selçuk, G. S., Çalışkan, S., \& Erol, M. (2008). The Effects of Problem-solving Instruction on Physics Achievement, Problem-solving Performance and Strategy Use. Latin American Journal Physics Education, 2(3), 151 - 166.

Shishigu, A., Bashu B., Tesfaw, B., \& Gadisa, S. (2016). The Effect of Problem Based Learning (PBL) Instruction on Students' Motivation and Problem-solving Skills of Physics. EURASIA Journal of Mathematics Science and Technology Education, 13(3), 857-871. https:/ / doi.org/10.12973/eurasia.2017.00647a

Shishigu, A., Hailu, A., \& Anibo, Z. (2017). Problem-Based Learning and Conceptual Understanding of College Female Students in Physics. EURASIA Journal of Mathematics, Science and Technology Education, 14(1), 145154. https:/ / doi.org/10.12973/ ejmste/78035

Taasoobshirazi, G., \& Carr, M. (2008). A review and critique of context-based physics instruction and assessment. Educational Research Review, 3(2), 155-167. https:/ / doi.org/10.1016/j.edurev.2008.01.002

Trowbridge, D., \& McDermott, L. (1981). Investigation of student understanding of the concept of acceleration in one dimension. American Journal of Physics, 49(3), 242 - 253. https:/ / doi.org/10.1119/1.12525

Walsh, L. (2009). A phenomenographic study of introductory physics students: Approaches to problem-solving and conceptualization of knowledge (Doctorate Thesis), Dublin Institute of Technology, Dublin. https:/ / doi.org/10.21427/D73598

Walsh, L. N., Howard, R. G., \& Bowe, B. (2007). Phenomenographic study of students' problem-solving approaches in physics. Physical Review Special Topics - Physics Education Research, 3, 020108. https:/ / doi.org/10.1103/PhysRevSTPER.3.020108

Wilson, J. D., \& Buffa, A. J. (2002). College Physics (5th ed.). Englewood Cliffs, NJ: Prentice Hall. 
Young, H. D., Freedmand, R. A., Dandin, T. R., \& Lewis, A. (1999). Sears and Zemansky's University Physics (10th ed.). New York, Addison Wesley.

Yu, K. C., Fan, S. C., \& Lin, K. Y. (2014). Enhancing students' problem-solving skills through context-based learning. International of Science and Mathematics Education, 12, 64-78.

Zhu, Z. (2007). Gender differences in mathematical problem solving patterns: A review of literature. International Education Journal, 8(2), 187-203.

\section{http://www.ejmste.com}

